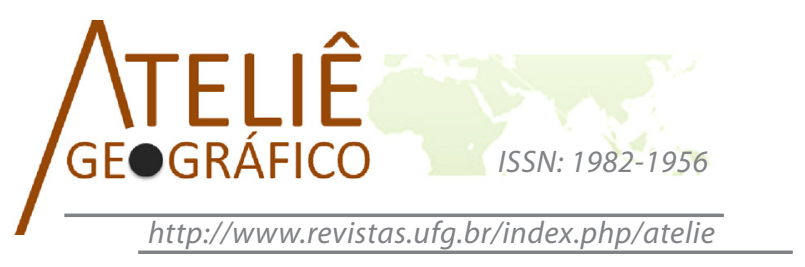

\title{
As festas populares como objeto de estudo: contribuições geográficas a partir de uma análise escalar
}

\author{
Popular festivals as an object of study: geographical \\ contributions from a scale analysis
}

\section{Fêtes populaires comme un objet d'étude: contributions géographiques à partir d'une analyse d'échelle}

\author{
Luana Moreira Marques \\ Universidade Federal de Uberlândia \\ luanageotur@yahoo.com.br \\ Carlos Rodrigues Brandão \\ Universidade Estadual de Campinas - UNICAMP \\ carlosdecaldas@gmail.com
}

\begin{abstract}
Resumo
O presente ensaio propõe um modelo de análise escalar das festas populares. Sabe-se que elas são manifestações culturais que fazem parte da estrutura social comunitária, compondo, interagindo, influenciando e modificando o cotidiano. Para entender a coexistência entre elementos aparentemente opostos como a reza e o baile, ou a devoção e a diversão é fundamental laçar o olhar sobre a festa a partir de diferentes escalas. Numa rápida observação da manifestação cultural, pode-se crer que ela se tornou espetáculo ou se reduziu a um resíduo folclorizado, mas a festa é complexa e tende a abarcar, em seu âmago, tanto o espetáculo como a tradição, num rico movimento de renovação constante a partir de sua própria essência. Assim, é possível atentar tanto às suas ressignificações, apropriações e espetacularização num âmbito macro-escalar, como aos detalhes e singularidades da festa no contexto micro-escalar. A fundamentação do ensaio se deu com uma revisão bibliográfica multidisciplinar, além da observação e reflexão sobre algumas festas populares brasileiras. Diante disso, a proposta se coloca, de maneira mais ampla, como uma forma de interpretação sistêmica da festa popular no tempo e no espaço.
\end{abstract}

Palavras-chave: geografia, cultura, escalas, espetáculo. 


\begin{abstract}
This essay proposes a scale analysis model for popular festivals. It is known popular festivals are cultural manifestations that are part of the community social structure; composing, interacting, influencing and modifying everyday life. To understand the coexistence of seemingly opposing elements such as prayer and dance, or devotion and entertaining is fundamental to look upon the party from different scales. With a quick look at cultural manifestation, one can believe that it has become a spectacle or that it has been reduced to a folkloric residue, but the festival is complex and tends to embrace, at its core, both spectacle and tradition in a rich movement of constant renewal starting from its very essence. Thus, it is possible to pay attention both to its resignifications, appropriations and spectacularization in a macro-scale level, and to the detail and festival singularities in a micro-scale context. The basis of this essay occurred with a multidisciplinary bibliographic review as well as the observation and reflection on a number of Brazilian popular festivals. Therefore, the proposal stands, more broadly, as a form of systemic interpretation of the popular festival in time and space.
\end{abstract}

Keywords: geography, culture, scales, spectacle.

\begin{abstract}
Résumé
Cet essai propose un modèle d'analyse d'échelle pour les fêtes populaires. Il est connu que les fêtes populaires sont des manifestations culturelles qui font partie de la structure sociale de la communauté, de la composition,de l' interagissant, de l'influençant, et de la modifiant de la vie quotidienne. Pour comprendre la coexistence d'éléments apparemment opposés tels que la prière et de la danse, ou de dévotion et de divertir est fondamental regarder les fêtes à différentes échelles. Un rapide regard sur la manifestation culturelle, on peut croire que ce est devenu un spectacle ou qu'il a été réduit à un résidu folklorique, mais la fête est complexe et tend à embrasser, à sa base, à la fois du spectacle et de la tradition dans un mouvement riche du renouvellement constant à partir de sa essence. Ainsi, il est possible de faire attention à la fois à ses resignifications, ses crédits et ses spectacularisation à un niveau macro-échelle, et a son détail et ses singularités dans un contexte micro-échelle. La base de cet essai se est produite avec une revue bibliographique multidisciplinaire ainsi que l'observation et la réflexion sur un certain nombre de fêtes populaires brésiliennes. En conséquence, la proposition actuelle, plus largement, comme une forme d'interprétation systémique de la fête populaire dans le temps et l'espace.
\end{abstract}

Mots-clés: la géographie, la culture, les échelles, spectacle.

\title{
Introdução
}

O presente ensaio é o resultado de estudos e reflexões teóricas aliadas a pesquisas sobre algumas festas populares brasileiras como o Carnaval, os Festivais de Parintins e as Festas Juninas, além de imersões em campo em manifestações religiosas do Triângulo Mineiro como as festas de Santos Reis de Martinésia, de 2010 e 2011, e o Congado de Uberlândia, dos anos de 2011 e 2013. Apesar da reflexão se fundamentar em observações empíricas, destaca-se que este não é um trabalho descritivo ou estudo de caso, mas uma ponderação teórica que propõe um modelo de análise das festas populares a partir das escalas.

Buscou-se entender as festas populares como manifestações culturais que fazem parte da estrutura social comunitária e identificar suas interações, influências e 
modificações perante alguns elementos do meio. A priori, são abordados conceitos que tangem as festas como: cultura e cultura popular. Em seguida, trata-se a festa e suas características, além da discussão sobre alguns elementos que a modificam/alteram. Por último, propõe-se um modelo de análise escalar sobre as festas. Tal proposta permite atentar tanto a seus detalhes e singularidades num contexto micro-escalar, como a suas ressignificações, apropriações e espetacularização no âmbito macro-escalar. Para fundamentar este ensaio foram utilizadas as obras de autores da geografia, história, sociologia e antropologia, com foco nas obras de Nestor Canclini, Michel de Certeau, Rita Amaral, Paul Claval, e Roger Chartier.

Embora haja uma grande variedade de estudos sobre festas populares no século $\mathrm{XX}$, o caráter predominantemente descritivo e pouco analítico destas obras dificulta $\mathrm{o}$ entendimento das inter-relações estabelecidas a partir das manifestações festivas. Isto se dá porque boa parte dos trabalhos em questão foram desenvolvidos por folcloristas que se limitaram a etnografar as práticas observadas em cada lócus e registrá-las. Não se pretende reduzir a importância destes levantamentos, bem como de seus métodos e pesquisadores, entretanto considera-se importante transcender o olhar etnográfico e compreender as relações que se estabelecem por de traz das práticas observadas em campo.

Nesse contexto, a festa abre inúmeras possibilidades para ser discutida e trabalhada na geografia. Para Gravari-Barbas (2011) a festa na cidade reflete as realidades sociais, econômicas e políticas deste espaço. Assim, os eventos festivos podem contribuir com o entendimento do urbano na contemporaneidade:

Un ensemble de facteurs incite toutefois à penser que les événements festifs organisés dans la ville contemporaine - par leur nature, leurs objectifs et les pratiques qu'ils induisent - se positionnent comme des médiateurs susceptibles de contribuer à la connaissance de l'urbain en ce début du $\mathrm{XXI}^{\mathrm{e}}$ siècle. ${ }^{1}$ (GRAVARI-BARBAS, 2011, p. 185)

Nessa perspectiva, pode-se observar que o estudo das festas e manifestações religiosas é um fértil campo de exploração na geografia e tem sua importância fundamentada no reflexo das práticas religiosas no espaço. Elas o transformam, assim como modificam o sujeito e seu cotidiano como um todo sistêmico, integrado e em constante movimento.

Destaca-se que a geografia é uma área do conhecimento que estuda o espaço e suas relações. Ela interliga elementos ambientais, sociais, econômicos, culturais, entre outros. Considerando que os indivíduos se relacionam entre si e com o meio, esta ciência possibilita a realização de amplas análises e interpretações das práticas sociais no espaço.

Além da geografia, os estudos sócio-culturais também têm recebido contribuições de diversas outras áreas do conhecimento como história, antropologia e ciências sociais que têm a festa como objeto de estudo. Cada uma a conceitua e a trabalha de acordo

1. Tradução livre: "Um conjunto de fatores incita, no entanto, a pensar que os eventos festivos organizados na cidade contemporânea - por sua natureza, seus objetivos e as práticas que eles induzem - se posicionam como mediadores suscetíveis de contribuir ao conhecimento do urbano neste início do século XXI." 
com seus objetos de pesquisa e conjecturas científicas e, apesar de terem objetos de estudo diferentes, contribuem para a reflexão geográfica, tendo em vista que o espaço e as demais categorias de análise estão ligadas em redes e devem ser pensadas a partir de uma abordagem sistêmica.

\section{As festas populares como categoria de análise cultural}

Antes de adentrar no universo das festas populares, considera-se importante entender o que é cultura, tendo em vista que as festas são elementos culturais e estão presentes no meio social. Um dos conceitos de cultura mais difundidos e utilizados até meados do século XIX é o de Tylor (1871, apud White, 1960): “Cultura [...] é o todo complexo que inclui conhecimento, crença, arte, moral, lei, costumes e todas as outras capacidades e hábitos adquiridos pelo homem como membro da sociedade". Verificase que boa parte dos conceitos formulados a partir de então são derivados da definição tyloriana que destaca a cultura a partir das singularidades e peculiaridades do homem.

Nesse contexto o geógrafo francês Paul Claval (2001) define cultura como:

[...] a soma dos comportamentos, dos saberes, das técnicas, dos conhecimentos e dos valores acumulados pelos indivíduos durante suas vidas e, em uma outra escala, pelo conjunto dos grupos de que fazem parte. A cultura é herança transmitida de uma geração a outra. Ela tem suas raízes num passado longínquo, que mergulha no território onde seus mortos são enterrados e onde seus deuses se manifestaram. Não é portanto um conjunto fechado e imutável de técnicas e de comportamentos. [...] (CLAVAL,2001, p. 63)

Claval segue a mesma linha de Tylor quando destaca os hábitos de cada ser. Mas também reforça o fator da transitoriedade e do movimento que configura a cultura e suas relações. A cultura é um elemento inerente ao indivíduo e por isso ela apresenta oscilações, interações, trocas e intercomunicações. Sem o movimento a cultura se torna folclore, isto é, fica estática e se perde na previsibilidade e falta de autonomia. Este cenário abre precedentes para sua transformação em patrimônio imaterial a ser apropriado e consumido como simulacro/representação da cultura popular pelo sistema capitalista.

Seguindo a necessidade de definição e discussão do termo "cultura" Certeau (1995), destaca sua dicotomia:

[...] a cultura oscila mais essencialmente entre duas formas, das quais uma sempre faz com que se esqueça da outra. De um lado, ela é aquilo que "permanece"; do outro, aquilo que se inventa. Há, por um lado, as lentidões, as latências, os atrasos que se acumulam na espessura das mentalidades, certezas e ritualizações sociais, via opaca, inflexível, dissimulada nos gestos cotidianos, ao mesmo tempo os mais atuais e milenares. Por outro, as irrupções, os desvios, todas essas margens de uma inventividade de onde as gerações futuras extrairão sucessivamente sua "cultura erudita". A cultura é uma noite escura em que dormem as revoluções de há pouco, invisíveis, encerradas nas práticas -, mas pirilampos, e por vezes grandes pássaros noturnos, atravessam-na; aparecimentos e criações que delineiam a chance de um outro dia. (CERTEAU, 1995, p. 239) 
As palavras de Certeau mostram a contradição e o movimento da cultura. Trata da possibilidade de incursão de novos elementos e aparições no meio social. Como a cultura não é estável/fixa, é possível observar certa latência em seus fluxos. Esta característica modifica paulatinamente as formas, características e estética das manifestações culturais, proporcionando-lhes uma dinâmica própria e singular. Portanto, a cultura é inventiva, é histórica, é processo e mudança.

Chartier (2003) toca na questão da classificação das culturas diferenciando-as e, "erudita" e "popular". Ele afirma que a cultura popular é diferente da erudita no que tange à forma, estética, expressão. Todavia, ambos os tipos se alimentam pela possibilidade das apropriações e reinvenções. No que diz respeito à categoria popular, ele explica que se trata de uma "invenção" dos intelectuais, primeiro os folcloristas, depois o ramo de sociologia, ontologia, história, entre outros. Não que o popular não exista como práticas e representações, mas que elas estão entranhadas no viver cotidiano, se entrelaçando na produção das relações sociais, são partes das experiências dos sujeitos sociais que se identificam em meio aos rituais, às festas, às crenças, etc.

erudito:

Chauí (2006, p. 13) aponta quatro elementos que distinguem o popular do

A distinção entre cultura/arte popular e erudita, embora seja realmente expressão e conseqüência da divisão social das classes, aparece como diferença qualitativa, que pode ser observada: a) na complexidade da elaboração (a arte popular é mais simples e menos complexa do que a erudita); b) na relação com o novo e com o tempo (a popular tende a ser tradicionalista e repetitiva, enquanto a erudita tende a ser de vanguarda e voltada para o futuro); c) na relação com o público (na popular, artistas e público tendem a não se distinguir, enquanto na erudita é clara a distinção entre o artista e o público); e d) no modo de compreensão (na arte popular, o artista exprime diretamente o que se passa em seu ambiente e é imediatamente compreendido por todos; na erudita, ele cria novos meios de expressão, de maneira que sua obra não é imediatamente compreensível a não ser para os entendidos, que por isso a interpretam para o restante do público). (CHAUÍ, 2006, p. 13)

Assim como Certeau (1995) e Chauí (2006), também concordamos que o popular e o erudito apresentam elementos que os distinguem um do outro. Entretanto, é certo que há uma comunicação entre tais categorias. Além disso, acreditamos que a diferença fundamental entre o popular e o erudito é a linguagem.

Para que um processo de comunicação obtenha êxito, é necessário que a mensagem enviada seja compreendida pelo emissor (quem remete) e pelo destinatário (quem recebe). Se a comunicação for produzida em via única, isto é, apenas remetida, não haverá compreensão e a falta de compreensão impede as trocas. Por outro lado, se as produções culturais utilizarem uma linguagem mais espontânea, sem se bloquear por um conjunto de normas, técnicas e pressupostos que endurecem as trocas, a comunicação será efetivada.

Pode-se afirmar então, que o popular é pautado na espontaneidade, na comunicação oral que se dissemina a partir dos valores e pressupostos subjetivos de cada 
indivíduo. Com isso ela traça uma coletividade que se comunica, que troca e assume as práticas locais.

É importante destacar que o popular não se caracteriza por um tipo de cultura simplificada. Ao contrário, as riquezas observadas nas nuances, falas e comportamentos assumidos pelo povo são infinitos. E isso é garantido pela fluidez que se refaz a cada dia e movimenta todo o processo de (re)construção cultural.

Chartier (2003) relata que a cultura popular apresenta características específicas, como pode ser observado a seguir:

O "popular" não se encontra no corpus que seria suficiente delimitar, inventariar e descrever. Antes de tudo, ele qualifica um modo de relação, uma maneira de utilizar os objetos ou as normas que circulam em toda a sociedade, mas que são recebidos, compreendidos, manipulados de diversas formas. (CHARTIER, 2003, p. 151-2)

No fragmento supracitado Chartier (2003) destaca a dificuldade de se tentar classificar e encaixar a cultura popular em padrões e rótulos. Nesta perspectiva ele enfatiza que o modo de agir, de se comportar frente aos estímulos, bem como as interações com o meio e com a matéria caracterizam o popular.

Nas pegadas de Chartier (2003) a definição de cultura popular proposta por Machado (2002), distancia a erudição, lembrada pelo "racionalismo científico", do popular e a relaciona às práticas e representações, como pode ser identificado no seguinte fragmento:

[...] De uma forma bem simples, podemos definir, em um primeiro instante, cultura popular como todas aquelas práticas e representações culturais vivenciadas no cotidiano de atores sociais específicos, distantes do racionalismo científico, como forma de recriação do seu universo: crenças, hábitos, costumes, conhecimento. (MACHADO, 2002, p. 335)

Assim como Chartier (2003) e Machado (2002), Canclini (2003) também afirma que o popular é caracterizado mais por práticas sociais e processos comunicativos do que por um amontoado de objetos. É comum verificar que, de modo geral, o senso comum relaciona o popular às baixas rendas, ao tradicional (no sentido de retrógrado e ultrapassado), subalterno, àquilo que não é moda, ao velho e, muitas vezes inapropriado e decadente. Isto se dá pela valorização midiática do novo, moderno, "cult", que é ao mesmo tempo oposto e inacessível às camadas populares. Neste sentido, Canclini (2003, p. 205) destaca que

O popular é nessa história o excluído: aqueles que não têm patrimônio ou não conseguem que ele seja reconhecido e conservado: os artesãos que não chegam a ser artistas, a individualizar-se, nem a participar do mercado de bens simbólicos "legítimos"; os espectadores dos meios massivos que ficam de fora das universidades e dos museus, "incapazes" de ler e olhar a alta cultura porque desconhecem a história dos saberes e estilos. (CANCLINI, 2003, p. 205) 
Diante disso, verifica-se que o popular e o erudito são diferentes e se complementam simultaneamente. Por isso, é possível observar injunções entre o popular e o erudito, tendo em vista que os seus limites não são impenetráveis, sobretudo nas artes, na música, na religiosidade e nas festas.

Se tratando de festa, é importante verificar quais elementos permeiam esta manifestação. Josef Pieper (1965 apud AMARAL, 2008) enumera doze características necessárias para compor uma festa. São elas:

1. Excepcionalidade;

2. Espontaneidade;

3. Valorização de alguma coisa perdida;

4. Significância que repousa puramente em si mesma;

5. Qualidade além de quantidade;

6. Contemplação;

7. Renúncia;

8. Esbanjamento;

9. Afeto;

10. Fruição;

11. Memória;

12. Afirmação do mundo.

Os doze princípios enunciados por Pieper (1965) proporcionam sentido às festas populares. Por outro lado é importante pensar nos pontos subjetivos desta proposição como a atribuição do "afeto", pois eles dificultam a mensuração e análise da manifestação. Destaca-se também a ausência de pontos-chave como o "mito" ou "vetor" de origem da festa. Em relação ao mito, o elemento que mais se aproxima dele é a contemplação, mas Pieper (1999) trata esta característica como engendramento do visual, do espetáculo, do olhar e não como símbolo a ser cultuado, como pode ser observado no seguinte fragmento:

From this it follows that the concept of festivity is inconceivable without an element of contemplation. This does not mean exerting the argumentative intellect, but the "simple intuition" of reason; not the unrest of though, but the mind's eye resting on whatever manifests itself. It means a relaxing of the strenuous fixation of the eye on the given frame of reference, without which no utilitarian act is accomplished. Instead, the field of vision widens, concern for success or failure of an act falls away, and the soul turns to its infinite object; it becomes aware of the illimitable horizon of realty as a whole..$^{2}$ (PIEPER, 1999, p. 17)

2. Tradução livre: "Disto resulta que o conceito de festa é inconcebível sem um elemento de contemplação. Isto não significa exercer o intelecto argumentativo, mas a intuição "simples" da razão, não agitação do embora, mas descansar a mente de olho em tudo se manifesta. Significa um relaxamento da fixação extenuante do olho no determinado quadro de referência, sem o qual nenhum ato utilitarista é realizado. Em vez disso, o campo de visão se amplia, a preocupação com o sucesso ou o fracasso de um ato desaparece, e a alma volta ao seu objeto infinito, torna-se ciente de horizonte ilimitado da realidade como um todo." 
Seguindo a linha de raciocínio de Pieper, porém com perspectivas distintas talvez por advir de escolas diferentes - propõe-se outros elementos característicos e indispensáveis às festas que modificam e complementam a lista formulada pelo autor em questão:

1. Mito ou vetor de origem;

2. Sujeitos da festa;

3. Relações sociais;

4. Singularidades;

5. Espontaneidade;

6. Estética;

7. Esbanjamento;

8. Memória;

9. Renúncia;

10. Espaço;

11. Estrutura física e equipamentos;

12. Sentimento de pertença.

Permaneceram cinco características propostas por Pieper (singularidades; espontaneidade; esbanjamento; memória; e renúncia) e foram inseridos sete novos elementos (mito ou vetor de origem; sujeitos da festa; relações sociais; estética; espaço; estrutura física e equipamentos; e sentimento de pertença). O mito ou vetor de origem é o eixo central da festa. A partir dele justifica-se a manifestação. Os sujeitos são aqueles indivíduos que participam da festa. Neste caso incluem-se tanto os organizadores, quanto os expectadores. As relações sociais são caracterizadas pelas inter-relações entre os indivíduos na festa. São marcadas pelas trocas comerciais e simbólicas. As singularidades diferenciam a festa e possibilitam sua identificação perante todas as outras manifestações. Ligada diretamente às singularidades, a espontaneidade permite o fluir e movimentar da festa. Sem ela a manifestação "endurece" e perde sentido. O sexto elemento é a estética. Toda festa é permeada por esta característica que também proporciona singularidades e espontaneidade. O esbanjamento também é fator indispensável, pois está ligado aos excessos. As festas de um modo geral são regadas à fruição, ao esbanjamento e excesso, tanto no lado físico, como social, moral, etc. A memória é o oitavo elemento indispensável à caracterização das festas, está ligada à história e origem da manifestação. Destaca-se também a renúncia. Os sujeitos da festa são marcados por histórias de renúncia que coroam seu permanecimento e continuidade nas manifestações. Tem-se ainda o espaço, elemento que unido à estrutura física e aos equipamentos ( $11^{\mathrm{a}}$ característica $)$, sustentam fisicamente a manifestação. A festa não pode ser realizada sem um lócus e infra-estrutura, mesmo que sejam ínfimos. Por último, observam-se os valores de pertença dos sujeitos em relação aos demais elementos. Esta característica permite o estabelecimento de redes e laços entre todos os outros pontos citados e é um dos principais responsáveis pela articulação da festa. 
Observa-se, portanto, que a festa é marcada pela formação de redes e seu dinamismo depende desta estrutura flutuante. Os sujeitos a realizam se misturam temporariamente a instituições, organizações privadas, entre outras corporações e juntos atuam na festa, cada um a seu modo, realizando suas funções e defendendo interesses próprios. Assim, a produção deste evento passa a não ser mais domínio exclusivo da comunidade e o popular se envereda por caminhos antes não percorridos, ganhando novas influências, conforme destaca Canclini (2003):

A evolução das festas tradicionais, da produção e venda de artesanato revela que essas não são mais tarefas exclusivas dos grupos étnicos, nem sequer de setores camponeses mais amplos, nem mesmo da oligarquia agrária; intervêm também em sua organização os ministérios de cultura e de comércio, as fundações privadas, as empresas de bebidas, as rádios e a televisão. Os fenômenos culturais folk ou tradicionais são hoje o produto multideterminado de agentes populares e hegemônicos, rurais e urbanos, locais, nacionais e transnacionais. Por extensão, é possível pensar que o popular é constituído por processos híbridos e complexos, usando como signos de identificação elementos procedentes de diversas classes e nações. Ao mesmo tempo, podemos tornarnos mais receptivos frente aos ingredientes das chamadas culturas populares que são reprodução do hegemônico, ou que se tornam autodestrutivos para os setores populares, ou contrários a seus interesses: a corrupção, as atitudes resignadas ou ambivalentes em relação aos grupos hegemônicos. (CANCLINI, 2003, p. 220-1)

Essa multi-intervenção movimenta a festa e possibilita aos seus participantes novos usos, interesses e percepções. Por fim, Amaral $(2001,2008)$ em seus trabalhos sobre as festas brasileiras, destaca o caráter mediativo e comunicacional destas manifestações. A autora afirma que as festas estabelecem relações de comunicação intersubjetivas entre conteúdos culturais, sociais, políticos e econômicos, além de serem instrumentos de mediação entre elementos tangíveis e intangíveis, objetivos e subjetivos, etc., como pode ser observado no seguinte fragmento:

[...] a festa é uma das vias privilegiadas no estabelecimento de mediações da humanidade. Ela busca recuperar a imanência entre criador e criaturas, natureza e da cultura, tempo e eternidade, vida e morte, ser e não ser. A presença da música, da alimentação, da dança, dos mitos, das máscaras, atesta com veemência esta proposição. A festa é, ainda, mediação entre os anseios individuais e coletivos, mito e história, fantasia e realidade, o passado, presente e futuro, entre "nós" e os "outros", revelando e exaltando as contradições impostas à vida humana pela dicotomia natureza e cultura. Mediando os encontros culturais e absorvendo, digerindo e transformando em pontes os opostos tidos como inconciliáveis. A festa é a mediação; o diálogo da cultura com si mesma. (AMARAL, 2008, p. 5)

Diante das idéias e conceitos apresentados, observa-se que as festas populares são manifestações da cultura local de diversos destinos brasileiros. Entretanto, é possível visualizar determinados fenômenos se infiltrando e alterando o sentido destas festas. São eles: o sistema capitalista e suas atividades comerciais; a modernização; e a formação de redes de interação e comunicação. 
O capitalismo e suas atividades comerciais se inserem nas festas visando comercializar bens e serviços. Todavia, verifica-se que as relações de trocas econômicas destoam o sentido primordial de boa parte das festas populares que tem um elemento sagrado como eixo central da manifestação e, portanto, são consideradas manifestações sagradas ou sacro-profanas. Exemplos disto são: a instalação de parques de diversões, a venda de souvenires de santos padroeiros, a comercialização de bebidas, entre outros tipos de bens durante a realização do evento. Em casos como estes os empresários se apropriam do lugar da festa e o utilizam como espaço para reprodução do capital.

Amaral (2008) classificou as festas brasileiras em: Sacro-profanas, Sagradas, Profanas, Festivais e Festividades. Nas Sacro-profanas há a presença do elemento mítico-religioso, mas os festejos profanos têm grande relevância, como é o caso do Festival de Parintins e das Festas de São João. As festas Sagradas são aquelas em que o conteúdo mítico-religioso tem mais força que os elementos profanos, como as festas do Divino Espírito Santo e as Festas de Santos Reis. As festas Profanas são aquelas sem conteúdo sagrado como base. Exemplos disso são as festas de Peão Boiadeiro e a Oktoberfest. Já os festivais são os eventos que envolvem a exposição de produtos, elegendo inclusive uma representante anual (rainha, rei e/ou princesas). Tem-se como exemplo a Festa Nacional da Uva e o Festival da Imigração Alemã. Por último destacamse as festividades, caracterizadas por seu cunho lúdico e independente de sentido míticoreligioso e histórico-social como os bailes e micaretas.

Embora todos esses segmentos festivos pertençam à categoria festa, alguns foram produzidos pelo e para o capitalismo como as festas Profanas e os Festivais. Verificam-se ainda que nos demais tipos o capital tem exercido uma forte influência, fazendo inclusive com que determinadas manifestações transponham barreiras, isto é, percam seu caráter essencialmente sagrado e se profanizem. Muitas das atuais festas Sacro-profanas foram, na sua origem, essencialmente sagradas e outras que ainda são consideradas sagradas tendem a ser futuramente classificadas como eventos sacro-profanos, como é o caso da festa de Santos Reis.

A inserção capitalista na festa é espacial. Nela os comerciantes se apropriam do lugar. Nesse sentido é importante diferenciar os termos "lugar" e "espaço", uma vez que constituem categorias geográficas diferentes. O lugar é onde acontecem as relações, onde ocorrem as apropriações emocionais, físicas, simbólicas que permitem a formação da identidade. O "lugar da festa" pressupõe identificação/pertencimento com a área em questão, independente de extensão territorial ou domínio legal. Carlos (1996) afirma que:

O lugar guarda em si e não fora dele o seu significado e as dimensões do movimento da história em constituição enquanto movimento da vida, possível de ser apreendido pela memória, através dos sentidos [...] é produto das relações humanas, entre homem e natureza, tecido por relações sociais que se realizam no plano do vivido o que garante a construção de uma rede de significados e sentidos que são tecidos pela história e cultura civilizadora produzindo a identidade, posto que é aí que o homem se reconhece porque é o lugar da vida. O sujeito pertence ao lugar como este a ele, pois a produção do lugar liga-se indissociavelmente a produção da vida. (CARLOS, 1996, p. 22) 
O espaço, por outro lado, é uma categoria que denota maior amplitude, pois se refere ao meio, a seus elementos (naturais, culturais, sociais, etc.) e às relações estabelecidas entre eles. Destaca-se que o espaço não deve ser entendido pelos pesquisadores das humanidades simplesmente como área, isto é, um espaço territorial demarcado com pontos limítrofes e sem interferências, dicotomias e interações com o ambiente, pois esta perspectiva conceitual leva à perda das observações relacionais e questões provocadas pelo indivíduo no meio.

Um segundo fenômeno que tem modificado as festas populares é a modernização. É possível observar durante os preparativos destes eventos a substituição de equipamentos e modos de produção rudimentares por outros mais modernos que facilitam seu preparar/ fazer. Nas Festas de Santos Reis, por exemplo, não se costumam mais fazer os Giros de Folia a pé, pois são contratados motoristas com Vans para levar os foliões. Também não é rotineiro abater animais de grande porte como bois ou vacas nas fazendas, mas levá-los ao frigorífico e receber a carne já desossada da empresa.

A modernização facilita o preparo da festa, porém também modifica sua essência e estética. A praticidade de se decorar um ambiente com flores artificiais de plástico, por exemplo, exerce um apelo muito forte sobre a dificuldade de se produzir flores de papel para a ornamentação do mesmo salão. O problema neste caso é que a sabedoria popular o saber fazer - se perde com o tempo. Este cenário se agrava perante a constatação de que a deterioração dos conhecimentos tradicionais tem sido observada em outras áreas da festa como no preparo de refeições, na confecção de roupas, na montagem de estruturas, entre outras.

É fato que as festas populares, em geral, não conseguiriam prover alimentos e se organizarem frente à crescente demanda sem as tecnologias. Suas realizações também não seriam possíveis sem os automóveis para a locomoção entre grandes distâncias. Portanto, é inegável que as modificações alteram as dinâmicas da festa. No entanto, o novo e moderno não anulam a essência do que já existe. Ao contrário, proporcionam novos movimentos, práticas e interações. Neste sentido, é importante relembrar que a cultura é maleável e por isso as transformações alcançadas pelas festas populares são, teoricamente, previsíveis e devem ser encaradas com cautela e parcimônia, pois interferir em seu curso pressupõe tirar-lhes a autenticidade.

Canclini (2003) ainda visualiza ações positivas a partir da inserção de elementos modernos aos tradicionais. Para ele

[...] a reelaboração heterodoxa - mas autogestiva - das tradições [a partir da modernização] pode ser fonte simultânea de prosperidade econômica e reafirmação simbólica. Nem a modernização exige abolir as tradições, nem o destino fatal dos grupos tradicionais é ficar de fora da modernidade. (CANCLINI, 2003, p. 239)

Entretanto, para que um cenário positivo como o citado ocorra, é necessário que o domínio e autonomia da festa continuem com a comunidade, caso contrário ela passará a sofrer as consequências da descaracterização moderna e perda da identidade. 
A globalização com suas redes de interação e comunicação também são fatores que modificam diretamente a cultura popular e as festas. Alguns eventos têm alcançado um número bem maior de espectadores devido às ferramentas de comunicação como a televisão, internet, rádio e jornais. De acordo com Ferreira (2001) e Amaral (2001), a festa é um instrumento de comunicação e é através deste elemento que ela sobrevive ao longo do tempo.

A partir do advento e crescimento de novas formas de comunicação e redes, um novo público se integra à festa. Todavia, tal demanda se liga à manifestação por razões diversas e muitas vezes diferentes das tradicionais, isto é, o louvor ao mito de origem - no caso das festas sagradas ou sacro-profanas. Este cenário causa estranheza e incompatibilidade entre os de dentro (pessoas que tradicionalmente fazem a festa) e os de fora (aqueles que recentemente participam da festa). Essa mixagem de sujeitos confere um novo sentido à manifestação e reforça sua maleabilidade e flexibilidade. Há então uma coexistência entre indivíduos que é aparentemente pacífica, mas apresenta uma latência em seu interior.

A festa se dá pela oralidade, pelo ritual, pela doação e forma um ciclo exterior ao tempo e ao espaço. Ela é dinâmica, se reinventa, transforma e se insere na globalidade, agregando novos símbolos e se metamorfoseando. Dá-se origem então a uma nova manifestação, com elementos renovados, mas formulados a partir do tradicional, dos cheiros, da fé, das cores e dos valores.

Neste sentido, a festa recruta o indivíduo e forma o coletivo que trabalha para a festa e pelo mito. De acordo com Santos; Alves; e Lima (2004),

Como a festa é para os Santos, este atua como um mediador entre os participantes. Fazê-la para os Santos inclui a possibilidade de juntar até mesmo aquelas pessoas que têm diferenças entre si. Trabalhar para o Santo significa tolerância, prudência e ponderação, pois a festa tem essa capacidade de juntar os diferentes na realização das festividades. (SANTOS; ALVES; e LIMA, 2004, p. 213)

As festas, sobretudo as religiosas, são repletas de signos, significados e alegorias, tendo como vetor central um mito de origem - um elemento de adoração e/ou admiração - que dá sentido à festa. O mito é necessário ao ser humano no sentido de justificar/ responder a questões inatingíveis pela ciência. Dessa forma, cria-se uma rede simbólica, que busca no imaginário individual, no subconsciente, no mítico, na filosofia, na religião, enfim, em artifícios não mensuráveis, respostas que sustentem a humanidade.

Diante das premissas expostas, verifica-se que as festas populares são manifestações culturais de movimento e fluxo. Para entendê-las como um todo complexo e sistêmico é importante observá-las a partir das escalas - proposta tratada a seguir.

\section{As escalas da festa}

À medida que as festas populares são infiltradas por elementos comunicacionais e capitalistas elas passam a atrair um maior público que não tem identidade e sentimento 
de pertença com a manifestação e tende a enxergá-la como espetáculo e produto a ser consumido. Ao mesmo tempo não se devem desconsiderar os atores sociais que produzem a festa e estão no núcleo desta, trabalhando pelo santo e considerando/buscando suas graças. Estes enxergam o evento predominantemente na perspectiva do sagrado. Observase então uma coexistência de dois públicos e dois momentos num mesmo tempo-espaço.

Para melhor entender essa questão, sugere-se vislumbrar o corpo da festa a partir de uma metodologia escalar. As escalas ${ }^{3}$ são utilizadas para quantificar tamanhos, volumes, grandezas, enfim, dimensionar elementos. Quanto maior a escala, maior o universo a ser tratado e menor seus detalhes, ou seja, uma macro-escala demonstra amplitude, já uma pequena escala ou micro-escala é focada nos detalhes, na essência, no que há de mais significativo do objeto de estudo.

Observar a festa numa perspectiva de escalas possibilita enquadrar tanto os atores sociais que a realizam quanto os que a consomem, demonstrando a unicidade e a riqueza desta manifestação. Neste sentido, Ricoeur (2007, p. 222) afirma: "Ao mudar de escala, não vemos as mesmas coisas maiores ou menos, em caracteres grandes ou pequenos, como disse Platão na República sobre a relação entre a alma e a cidade. Vemos coisas diferentes." Diante disso, propõe-se utilizar duas escalas nesse estudo: uma micro, abordando os detalhes da festa e outra macro, que possibilita uma visão geral do evento. Pretende-se assim entender as transformações, reproduções e ressignificações das festas populares no tempo-espaço.

A Figura 1 representa o "corpo" da festa. Nele é possível observar um núcleo, denominado "micro-escala"; e seu envoltório, tido como "macro-escala". Junto a esta analogia é possível agregar, ainda, o sagrado ao núcleo da festa e o profano a seu envoltório, observando sempre uma força interna (procedente do núcleo) e externa (adjacente do envoltório) que proporcionam interações e formam redes.

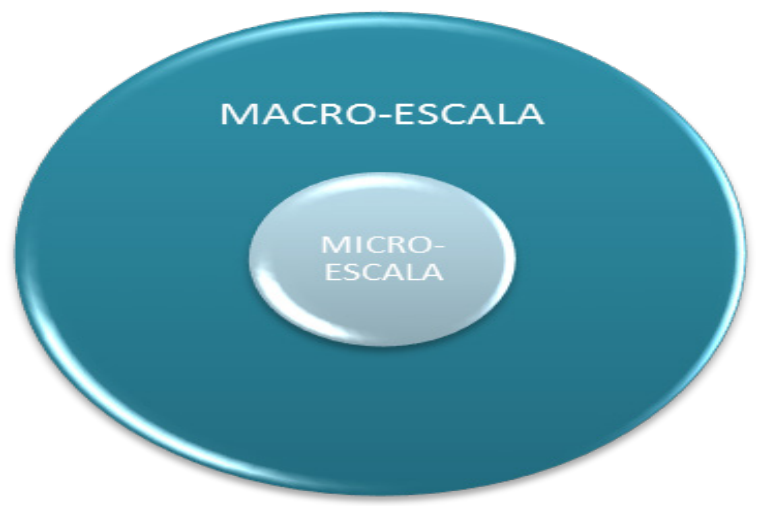

Figura 01: O corpo da festa: a macro e a micro-escala.

3. Embora o presente trabalho tenha um viés geográfico, ele não trata de escala cartográfica. A escala cartográfica - usada para referenciar mapas - possui princípios diferentes da escala numérica e, por isso, não cabe nessa pesquisa. 
Para elucidar o teor da micro e macro-escala tem-se o Quadro 01 com alguns de seus possíveis elementos e sujeitos:

Quadro 01: Exemplos de elementos e sujeitos da micro e macro-escala.

\begin{tabular}{|l|l|}
\hline Elementos e sujeitos da macro-escala & Elementos e sujeitos da micro-escala \\
\hline Vendedores ambulantes & Folias, grupo de cantadores \\
\hline Baile & Rezas \\
\hline Demanda em geral não devota ao mito da festa & Equipe de voluntários/devotos \\
\hline Som mecânico & Procissões \\
\hline Ilegalidades, drogas & Estabelecimento de vínculos afetivos \\
\hline Cobertura midiática & Mutirões de trabalho comunitário \\
\hline
\end{tabular}

Os elementos e sujeitos presentes na tabela não existem por si só. Eles estabelecem redes entre si e entre os elementos da escala oposta, isto é, há interações entre elementos e sujeitos intra e extra-escalares. Estas interações são dadas pelas forças presentes em cada escala - força interna na micro-escala e força externa na macro-escala. As forças internas se projetam para fora do núcleo da festa, enquanto as forças externas fazem o sentido contrário. O mecanismo em questão possibilita o equilíbrio da festa, mesmo diante de sua latência. Um exemplo do estabelecimento de redes extra-escalares é a comercialização de produtos advindos de vendedores ambulantes (pertencentes à macro-escala) para os sujeitos que preparam a festa (atores sociais da micro-escala).

A micro-escala é composta pelos sujeitos que preparam a festa. Considerando que boa parte deles é relativamente "fixa", isto é, desempenha as mesmas funções e serviços anualmente, pode-se afirmar que a micro-escala é mais resistente ou menos maleável que o restante do corpo da festa. Neste sentido, observa-se que o núcleo possui funções, hierarquias e formas de agir/sentir/pensar particulares.

Dentro da micro-escala é possível observar uma hierarquia dissimulada designada normalmente pelo(s) coordenador (es) da festa - geralmente representante(s) da comunidade local que por laços afetivos, políticos ou designação ocupa(m) este posto - e pelos sujeitos mais experientes em cada função. Para penetrar neste espaço é necessário conquistar a confiança das pessoas. Já para participar das atividades de maior responsabilidade são exigidos conhecimento, habilidade e prática, além do aval dos mandatários. Um exemplo disso é a participação nos mutirões para o preparo de refeições coletivas. Para chegar ao estágio que permite liberdade de escolha e ação dentro de uma cozinha de uma festa popular, o indivíduo deve passar por diversos estágios - todos informais e velados. Diante disso, verifica-se que o núcleo da festa consiste num grupo mais fechado e coeso com regras e princípio próprios. Estes fatores também determinam a manutenção de características tradicionais que dificultam a espetacularização da festa.

Portanto, no contexto micro-escalar, a festa não é um simulacro. Ao contrário, ela é real, intensa e modifica, mesmo que temporariamente, o cotidiano de seus atores 
sociais. É importante destacar que este ensaio não propõe uma visão fantasiosa de que a festa na micro-escala é original e fidedigna às tradições antepassadas. Ela continua apresentando movimento e se transformando, mas suas alterações, a princípio, não comprometem a essência da manifestação enquanto cultura popular.

Por outro lado, os elementos presentes na macro-escala são mais maleáveis, não possuem identidade com o lugar, variam de acordo com as situações e podem se expandir e se intensificar de acordo com os estímulos voltados a eles. O olhar da macro-escala sob a festa apresenta uma maior amplitude e, consequentemente, compreende o evento como um todo, não se apegando aos detalhes ou singularidades.

Na macro-escala é possível observar tendências de espetacularização da festa. O espetáculo/simulacro, neste contexto, é caracterizado pela reprodução do patrimônio cultural imaterial voltado a um público que não mantém laços identitários com a manifestação em questão. Esse tipo de prática é muito comum em atividades econômicas como o turismo. Criam-se assim alucinações culturais que preenchem o imaginário de um público pagante ou, conforme afirma Meneses (1996, p. 98), “[...] zumbis que voltam ao mundo dos vivos apenas para atender a solicitações externas de consumo [...]".

A festa se torna espetáculo quando a comunidade perde sua autonomia. A partir de então a manifestação passa a ser produzida por outros sujeitos e instituições que aliam o evento a aspirações próprias, de cunho político, social, religioso, entre outros. Apropriada, a festa perde sua espontaneidade, autenticidade e movimento. Pasta Júnior (1992, p. 72 apud MACHADO, 2003, p. 36) afirma que "[...] isolada, administrada ou emoldurada, ela se transforma em outra coisa qualquer - festividade, comemoração, menos festa. Nesse sentido, ela demarca o limite da apropriação, porque é impossível transformá-la em mercadoria sem perdê-la. [...]".

Considerando a espetacularização dos elementos sociais, Certeau (1995) faz a seguinte colocação:

Uma vez que a capacidade de produzir é na realidade organizada segundo racionalidades ou poderes econômicos, as representações coletivas se folclorizam. As instâncias ideológicas metamorfoseiam-se em espetáculos. Excluem-se das festas tanto o risco como a criação (a aposta pelo menos mantém o risco). As fábulas para espectadores sentados proliferam nos espaços de lazer que tornaram possível e necessário um trabalho concentrado e "forçado". Em compensação, as possibilidades de ação acumulam-se onde se concentram meios financeiros e competências técnicas. Sob esse aspecto, o crescimento do "cultural" é a indexação do movimento que transforma o "povo" em "público". (CERTEAU, 1995, p. 198)

Uma das proposições para a perda do significado da festa na perspectiva macroescalar é dada pelo desenraizamento de seus atores sociais, modelo proposto por Bosi (1992). A autora destaca a dificuldade de se trabalhar a cultura popular num país de migrantes, onde teoricamente as raízes dos sujeitos sociais são arrancadas e a partir de então eles devem se estabelecer e se reproduzir num novo lócus. Bosi (1992) afirma que tais transições fazem com que haja uma perda da cultura, sobretudo quando a migração é feita no sentido campo-cidade. 
O desenraizamento proposto por Bosi (1992) pode ser um fator que distancia e/ou modifica os atores sociais da cultura popular. Entretanto, isoladamente ele não justifica a perda do sentido da festa. Em alguns casos, por exemplo, os sujeitos retornam regularmente a seus lugares de origem a fim de realizem suas festas, mesmo após terem migrado. É certo que migração não significa desenraizamento. Contudo, é possível observar que em muitas comunidades o retorno dos "filhos da terra" se dá, sobretudo, em função da festa e que mesmo enraizados em outros espaços, estes indivíduos mantém vínculos afetivos nos seus lugares de origem, ou seja, no lugar da festa.

Se o desenraizamento não é a chave para desvendar quais os vetores levam à perda do significado da festa, a mídia pode abrir caminhos para esta exploração. A alteração da festa pode ser observada a partir do crescimento da demanda de seus expectadores. Esta ampliação do público que busca a contemplação do espetáculo é despertada por instrumentos midiáticos que também atraem elementos do capital, sobretudo comerciantes ambulantes e barraqueiros ${ }^{4}$. Neste sentido, Canclini (2003, p. 257) afirma que "[...] A arte popular, que tinha ganhado difusão e legitimidade social graças ao rádio e ao cinema, reelabora-se em virtude dos públicos que agora tomam conhecimento do folclore através de programas televisivos."

A mídia atua diretamente na espetacularização da festa. As notícias veiculadas nos meios de comunicação de massa se espalham freneticamente e atingem boa parte da população que passa a enxergar o evento como forma de lazer e recreação. Assim, ele passa a ter uma nova demanda que desconhece o sentido sagrado da manifestação e anseia predominantemente por seus elementos profanos. A festa se torna, então, um evento desprovido de significado para a massa passiva de consumidores presentes na macro-escala. Cria-se, portanto, um grupo de espectadores e sujeitos passivos frente a uma cultura de consumo cada vez mais difundida, como afirma Certeau:

Instalada nos lazeres onde representa como um todo a compensação do trabalho, a cultura de consumo desenvolve nos espectadores a passividade da qual ela já é o efeito. Ela representa o setor onde se acelera, mais do que em qualquer outro lugar da nação, o movimento que reduz o número dos atuantes e multiplica o dos passivos. (CERTEAU, 1995, p. 201-2)

Os espectadores da festa são atraídos principalmente pela necessidade do consumo do tempo livre - tempo do não trabalho - por meio do lazer. Mas a manifestação em si, espetacularizada, também apresenta uma série de encantos e seduções que reforçam seu potencial atrativo, sobretudo no que diz respeito à estética da festa. Enquanto simulacro, a festa é dotada de polimentos, fineza, arredondamentos, apurações e contém um senso profissional que não está presente na aspereza da festa popular. Os detalhes denunciam a festa espetacularizada. As flores feitas de plástico ao invés de papel, as modelos televisivas que desfilam no lugar das moças da comunidade, os repórteres atrapalhando as conversas entre as comadres...

A festa espetacularizada é influenciada por uma gama de poderes e apresenta uma série de dinamismos e redes. Sua estrutura possibilita o estabelecimento de inter-

4. Comerciantes que se instalam temporariamente em barracas e tendas. 
relações sociais, econômicas e culturais que a caracteriza e lhe confere singularidades. Ela passa, então, a ser tomada e comercializada como produto cultural. Neste contexto, Canclini (2003) faz a seguinte colocação:

Pensemos em uma festa popular, como podem ser a festa do dia dos mortos ou o Carnaval em vários países latino-americanos. Nasceram como celebrações comunitárias, mas num ano começaram a chegar turistas, logo depois fotógrafos de jornais, o rádio, a televisão e mais turistas. Os organizadores locais montam barracas para a venda de bebidas, do artesanato que sempre produziram, souverirs que inventam para aproveitar a visita de tanta gente. Além disso, cobram da mídia para permitir que fotografem e filmem. Onde reside o poder: nos meios massivos, nos organizadores das festas, nos vendedores de bebidas, artesanatos ou souveris, nos turistas e espectadores dos meios de comunicação que se deixassem de se interessar desmoronariam todo o processo? Claro que as relações não costumam ser igualitárias, mas é evidente que o poder e a construção do acontecimento são resultado de um tecido complexo e descentralizado de tradições reformuladas e intercâmbios modernos, de múltiplos agentes que se combinam. (CANCLINI, 2003, p. 262)

Canclini (2003) relata a transformação da festa mediante a apropriação do capital. Ele destaca sua gênese como "celebração comunitária" e expõe seu crescimento a partir da mídia, dos turistas e a consequente espetacularização. Assim, a comunidade perde paulatinamente a autonomia da festa e seu poder passa a residir no domínio do capital. Este processo faz com que a micro-escala se reduza e a macro-escala ganhe densidade, tamanho e força.

A observação a partir da micro e da macro-escala possibilita entender as redes, os elementos e cenários das festas populares. O modelo escalar ainda permite fazer diversas associações. Uma delas é a relação da micro-escala à Festa de Participação e da macroescala à Festa de Representação, ambas propostas por Duvignaud (1983). Para o autor, as Festas de Participação incluem a comunidade local no núcleo da manifestação, isto é, teoricamente a população organiza e participa da festa. Isto propicia um sentimento de identidade e pertença em relação ao patrimônio imaterial em questão. Já as Festas de Representação são aquelas marcadas pela reprodução/simulação de práticas e elementos culturais voltados ao lazer e entretenimento de uma massa consumidora. É a festa espetacularizada, com atores, espectadores, sem densidade de valores ou sentimento de pertença. O modelo escalar consegue englobar e investigar tanto os elementos da Festa de Participação, quanto da Festa de Representação num único evento cultural. Isto aumenta o poder de análise de processos, contradições e dicotomias, além de permitir transitar pelas espacialidades e temporalidades da festa.

Destaca-se ainda que a micro e a macro-escala coexistem. Esta coexistência não é necessariamente pacífica. Há embates velados, redes, influências e forças que possibilitam o equilíbrio e a continuidade destas escalas como uma unidade/corpo festivo. É importante lembrar que tais estruturas são interdependentes, ou seja, a ausência da macro-escala fará com que a festa se reduza, essencialmente (apesar de não exclusivamente), ao espaço e tempo da devoção. Já a supressão da micro-escala levará à espetacularização do evento. 


\section{Considerações finais}

Estudar a festa popular é um desafio perturbador e prazeroso. Sua leveza, fluidez, estética, sonoridade, cores e sabores encantam o pesquisador ao mesmo tempo em que seus movimentos e dicotomias o provocam. Contraditoriamente, as festas fazem parte de um universo da representação, mas suas práticas são efetivamente reais; elas são livres ao mesmo tempo em que se prendem a redes sociais, econômicas e culturais; coexistem em diversos tempos e espaços... Estas características dão o tom das festas. Proporcionam a elas singularidades, unicidades. E tais riquezas e contradições fazem com que se reinventem e permaneçam ontologicamente.

As festas são, portanto, unidades onde coexistem sujeitos, motivações, elementos, estruturas, poderes, tempos e espaços diferentes. Todos eles se distribuem, relacionam, fundem e comunicam em redes.

A expropriação da festa da comunidade juntamente à ação do capital sobre esta manifestação determinará se ela será espetacularizada. Por outro lado, é importante destacar que mesmo que a festa seja tomada, comercializada e se torne um simulacro, a cultura popular é intrínseca ao homem e permanecerá viva enquanto ele existir. Por isso, sempre haverão reinvenções, ressignificações e metamorfoses autênticas no eixo cultural. Consequentemente, a cultura popular continuará a ser dotada de circuitos alternativos ao espetáculo produzido.

\section{Referências}

AMARAL, Rita. Festa à Brasileira: sentidos do festejar no país que "não é sério". Disponível em: <http://www.aguaforte.com/antropologia/festaabrasileira/festa.html>. 2001. Acesso em: 11 out. 2007.

. Festas, festivais, festividades: algumas notas para a discussão de métodos e técnicas de pesquisa sobre festejar no Brasil. In: Anais do II Colóquio Festas e Sociabilidades - CIRS/CASO/CEFET. Natal, 2008.

ARANTES, Antônio Augusto. O que é cultura popular. São Paulo: Brasiliense, 1990. BRANDÃO, Carlos Rodrigues. Folia de Reis em Mossâmedes. Rio de Janeiro: MEC/ FUNARTE, 1977.

BRANDÃO, Carlos Rodrigues. Folia, festa, procissões e romaria. In: A cultura na rua, Campinas: Papirus, 1989.

BOSI, Ecléa. Cultura e desenraizamento. In: BOSI, Alfredo. Cultura Brasileira: temas e situações. São Paulo: Ática, 1992.

BURKE, Peter. Cultura popular na Idade Moderna. São Paulo: Cia das Letras, 1989.

CANCLINI, Nestor Garcia. Culturas Híbridas: estratégias para entrar e sair da modernidade. 4 ed. São Paulo: Editora da Universidade de São Paulo, 2003.

CARLOS, Ana Fani Alessandri. O Lugar no/do mundo. São Paulo: Labur Edições, 2007. 
CARLOS, Ana Fani Alessandri. Turismo e a produção do não-lugar. In: YÁZIGI, E.; CARLOS, A. F.A.; CRUZ, R. de C. A. Turismo: espaço, paisagem e cultura. $3^{\mathrm{a}}$ ed. São Paulo: Hucitec, 2002. p. 25-37.

CERTEAU, Michel de. A cultura no plural. Campinas: Papirus, 1995.

CHARTIER, Roger. Formas e sentido, cultura escrita: entre distinção e apropriação. Campinas/SP: Mercado de Letras, 2003.

CHAUÍ, Marilena. Cidadania Cultural - O Direito à Cultura. São Paulo: Fundação Perseu Abramo, 2006.

CLAVAL, Paul. A geografia Cultural. 2a ed. Florianópolis: Editora da UFSC, 2001.

DUVIGNAUD, Jean. Festas e civilizações. Rio de Janeiro: Tempo Brasileiro, 1983.

FERREIRA, Maria Nazareth. As festas populares e a expansão do turismo. São Paulo: ECA/USP, 2001.

FREIRE, Gilberto. Características gerais da colonização portuguesa no Brasil: formação de uma sociedade agrária, escravocrata e híbrida. In: Casa grande e senzala. Rio de Janeiro: José Olympio, 1980. p. 04-87.

GRAVARI-BARBAS, Maria. Nouvelles fêtes, nouveaux lieux, nouvelles spatialités: Vers une géographie des événements festifs à Paris. Cidades: a cidade e a festa, Presidente Prudente, v. 8, n. 13, p.183-206, Jan./Jun 2011. Semestral.

LUCHIARI, Maria Tereza D. P. Urbanização turística: um novo nexo entre o lugar e o mundo. In: Luiz Cruz Lima (org.). Da cidade ao campo: A Diversidade do saber-fazer turístico. Fortaleza: Editora FUNECE/UECE, 1998.

MACHADO, Maria Clara Tomaz. Cultura popular: um contínuo refazer de práticas e representações. In: Rosangela Patriota; Alcides Freire Ramos. (Org.). História e cultura: espaços plurais. 1 ed. Uberlândia: Asppectus, 2002, v. 1, p. 335-345.

. Folia de Reis: liturgia do povo recriando o mistério da vida. In: MACHADO, Maria Clara Tomaz; PATRIOTA, Rosangela. (orgs.). Histórias \& Historiografia: perspectivas contemporâneas de investigação. Uberlândia: EDUFU, 2003.

MARTINS, José de Souza. O vôo das andorinhas: migrações temporárias no Brasil. In: . Não há terra para plantar neste verão: o cerco das terras indígenas e das terras de trabalho no renascimento político do campo. $2^{\mathrm{a}}$ ed. Petrópolis: Vozes, 1988.

MENESES, Ulpiano T. Bezerra de. Os "usos culturais" da cultura: contribuição para uma abordagem crítica das práticas e políticas culturais. In: CARLOS; CRUZ e YÁZIGI. (orgs.) Turismo: espaço, paisagem e cultura. São Paulo: Hucitec, 1996. p. 88-99.

RICOEUR, Paul. A memória, a história, o esquecimento. Campinas: Unicamp, 2007. PIEPER, Josef. In tune with the world: a theory of festivity. Indiana: St. Augustine's Press, 1999. 
SANTOS, Rosselvelt José; ALVES e LIMA, Roger. Turismo religioso e as festas rurais de Uberlândia (MG), o maior centro urbano da Bacia do Rio Araguari. In: LIMA, Samuel do Carmo; SANTOS, Rosselvelt José. (Orgs). Gestão Ambiental da Bacia do Rio Araguari: rumo ao desenvolvimento sustentável. Brasília: CNPq, 2004.

SPOSITO, Maria Encarnação Beltrão. A questão cidade-campo: perspectivas a partir da cidade. In: SPOSITO, M. E. B.; WHITACKER, A. M., Cidade e Campo: relações e contradições entre urbano e rural. São Paulo: Expressão Popular, 2006.

WHITE, Leslie A. O conceito de cultura. Educ. e Ci. Soc.; Rio de Janeiro, ano 5, 8 (14): 18-56; jun. 1960. (mimio).

WILLIAMS, Raymond. O campo e a cidade na história e na literatura. São Paulo: Cia das Letras, 1989.

Luana Moreira Marques

Doutoranda, mestre e bacharel em Geografia pela Universidade Federal de Uberlândia. Foi professora universitária nos cursos de Geografia da Universidade Estadual de Minas Gerais e da Universidade de Uberaba.

Universidade Federal de Uberlândia, Faculdade de Artes, Filosofia e Ciências Sociais, Laboratório de Geografia Cultural e Turismo. Av. João Naves de Ávila, 2106, Bloco 1H, Sala 19. Santa Mônica. Cep: 38400-902. Uberlandia, MG Brasil

E-mail: luanageotur@yahoo.com.br

Carlos Rodrigues Brandão

Doutor em ciências sociais pela Universidade de São Paulo (USP). Graduado em psicologia pela Pontifícia Universidade Católica do Rio de Janeiro (1965) e mestre em antropologia pela Universidade de Brasília (1974). Atualmente é professor colaborador do Programa de Pós-Graduação em Antropologia da Universidade Estadual de Campinas (UNICAMP) e professor visitante senior da Universidade Federal de Uberlândia (UFU).

Universidade Estadual de Campinas, Núcleo de Estudos e Pesquisas Ambientais. Cidade Universitária Zeferino Vaz. Distrito de Barão Geraldo. Cep: 13024-431 Campinas, SP - Brasil

E-mail: carlosdecaldas@gmail.com

Recebido para publicação em fevereiro de 2015 Aprovado para publicação em abril de 2015 